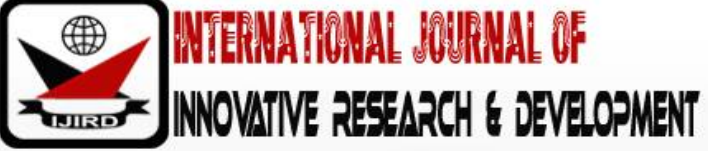

ISSN 2278 - 0211 (Online)

\section{Growing Women-Owned MSEs in Kenya}

\author{
Dr. Sangurah Ramari Mukhebi Robbert \\ Lecturer, School of Business and Economics, Moi University, Kenya
}

\begin{abstract}
:
Purpose: There is a growing discourse about a powerful untapped economic force in Africa, the women. The debate has triggered the formulation of female-specific entrepreneurship policy, which was the basis of this study. The study analyzed the mediating influence of the target policy in the relationship between women entrepreneurs' profile and their MSE growth. Methodology: The study design was a Cross-sectional Survey, anchored on Resource-based Theory. It based on a Positivist Paradigm and applied a Quantitative Multi-method approach. Using multi-stage sampling, 375 adult female entrepreneurs participated in the study. Data was analyzed through inferential methods; correlation coefficient and coefficient of determination.

Results: The results revealed there being direct and indirect relationships between and among variables. For example, the first step results showed significant mediating influence of resource support in the relationship between women entrepreneurs' motives and their venture growth; $b=.0784$, BCa CI $(.0443, .1207)$. Also, the R-squared (R-sq med=.1075) means the model explained $11 \%$ of the mediation relationship. The Preacher and Kelley Kappa-squared, $\mathrm{k}^{2}=.0829,95 \%$ BCa CI $(.0493, .1227)$, further showed there being a small but significant indirect relationship between entrepreneur's traits and growth through resource support, meaning that there are other mediators other than entrepreneurs' profile. This was further supported by the normal theory tests for indirect effect where $b=0784$, $z=3.8087$ and $p=<001$.
\end{abstract}

Keywords: Venture growth, women target policy, resource support programs, cross-sectional survey, Western Kenya Counties

\section{Introduction}

Women entrepreneurs have played an important role (Sangurah 2018 citing Nuogera, 2012 25) in driving firm creation and consequent economic growth (Acs et. al., 2011). Stakeholders are therefore discussing the women entrepreneurship topic from social, political, and academic fronts. Governments have developed policies to promote it as a means to socio-economic inclusion.

Despite its above importance however, the topic has attracted less research than entrepreneurship in general. The New Frontier' (Schwartz 1976)was amongst the earliest published works on subject. It examined characteristics, motivation, attitudes and barriers of female entrepreneurs. Several other studies followed, mainly focusing on personal characteristics that form the human capital (Brush, 2006: xiv, Brush 1992; Brush et al., 2006; Brush \& Hisrich 1999; Butler 2003in Sangurah 2018). They reveal that although women have owned firms ever since, public policy and popular media interest in their business ownership is relatively a recent phenomenon (Brush, 2006 18), a situation that has left them prone to both general and gender-specific challenges.

For example, in South Asia women economic potential is undermined by inequalities, including gender inequalities in access to education, health, employment, opportunities and resources and the rights of women to be treated equally with men. In this region, women's labor force participation rate is among the lowest in the world, and their entrepreneurship is untapped source of economic growth, social progress, and job creation. These impediments have therefore prevent South Asia from achieving truly equitable, inclusive and sustainable development(ESCAP 2015)

Since are disadvantaged in finding quality paid employment, they often look to other sources of income, notably entrepreneurship. Women-owned businesses however often lag behind male-owned enterprises in terms of size, productivity, and tend to be less profitable, with little potential for growth. Customs and social norms reinforce gender stereotypes, posing the main constraints for women entrepreneurship. Women have to balance business with the demands of family and household care. They are therefore forced to pursue business activities that offer less career opportunities, are less innovative and typically confined to traditional roles(OECD 2017 18)

A big percentage of females especially in developing countries are therefore necessity entrepreneurs, courtesy the many societal barriers and constraints they face that prevent them from fully developing their entrepreneurial potential (Marlow et. al., 2008 335). They face both general barriers for the development of MSMEs that include weak institutional support, lack of access to credit and services (KAM 2018 34); and gender-specific barriers related to uneven sharing of privatization gains like lack of collateral to acquire start-up capital, lack of networks, and traditional views on their role in society (Esim, 2001 9). 
Despite various recent policy interventions in Kenya, a bigger fraction of women still lag behind their male counterparts in the MSE sector. Gender disparities in terms of access to education, retention in school, transition from one level of education to the other and academic performance remains one of the challenges facing girl-child in the country. These disparities may be attributed to various factors, among them, societal beliefs and practices. Many women, especially in rural areas, therefore find themselves disadvantaged in establishing and running successful businesses due to lack of technical qualifications and inadequate market information (ROK-WEF 2009-2012).

This study therefore investigated if the niche resource support has enhanced the growth of women-owned MSEs or not. For example, the establishment of Women Enterprise Fund, Youth Enterprise Development Fund, Uwezo Fund, and Affirmative Action in education, employment and elective positions among others were positive steps towards ensuring resources reach the earlier on excluded women. It was also a testimony of the Kenya government's commitment to the realization of the 3rd Millennium Development Goal (MDG) on women empowerment and gender equity (ROK-WEF 20092012).

Using a Cross-sectional Survey design and guided by the Resource-based Theory, it tested four alternative hypotheses: There is a significant relationship between entrepreneurs' motives and their ventures' growth; There is a significant relationship between entrepreneurs' motives and resource support; There is a significant relationship between resource support and venture growth and; There is a significant mediating influence of resource support in the relationship between entrepreneurs' motives and venture growth.

\section{Methods}

Trans Nzoia and Bungoma counties are well endowed with resources, both natural and infrastructure that can be leveraged by entrepreneurs. In 2006 however, the joint research report by the UNDP and the Government of Kenya on district poverty indices classified Bungoma as a millennium district due to high poverty levels. Since the county is well endowed with human and natural resources, poverty was attributed to un-facilitated entrepreneurial efforts hence undeveloped entrepreneurial culture (UNDP/ ROK, 2006). Bwisa and Ongach (2013) allude that Women-owned MSEs in Trans Nzoia do not achieve optimum growth, a situation that has resulted in high poverty levels among the cohort.

This study was a justified Cross-sectional Survey Design since data was collected at a point in time. The researcher dealt with events that had already happened and he had no control over the variables (Mouton, 2005 55). The study therefore, utilized an ex-post facto strategy (Mouton, 2005 55-56). It adopted the positivist philosophy as it worked with an observable social reality and the end product formed a law-like generalizations similar to those produced by the natural scientists' (Remenyi et al., 1998 32). The study was guided by existing theories to develop hypotheses that were tested and accepted, leading to the development of a model (Saunders et. al., 2009 113).

The study population was female entrepreneurs who had accessed the government entrepreneurial development assistance in two counties, and had been operating in the last four years. Respondents were approached through registered groups. The study dealt with entrepreneurs in both rural and urban settings, across all sectors. The sampling frame was two thousands four hundred (2400) groups, of which nine hundred and twenty (920) were from Trans Nzoia and one thousand five hundred $(1,500)$ from Bungoma counties respectively.

Due to lack of statistics on female entrepreneur categories targeted, this study employed multistage sampling to provide more manageable and meaningful data. Simple random sampling was used to acquire the female MSME group leaders to be studied so as to minimize bias (Saunders et. al., 2009: 214). Snowballing through group leaders was then applied to access more of the difficult-to-identify hence less studied home-based women-owned MSEs (Neuman, 2006 223). Derived from Cochran (1963 75 in Israel 2013 1) sample determination table, 394 respondents participated in this study as respondents. This translated to ninety four registered groups.

Two data collection methods were employed; content analysis for secondary data and survey for primary data. Survey was used in this study because it enabled the researcher administer questionnaires and responses were recorded (Neuman 2006). Literature was reviewed to clarify the topic, identify the gaps and suitable theories and justify research project value (Leedy and Ormrod 2005142 \& Neuman, 2006 322). It let the researcher unravel the content in different sources, compare content across many texts and analyze the data exhaustively (Neuman (2006 323). It was important in that it provided the researcher with background information on the topic.

The data collected from the survey was analyzed through correlation/ inferential techniques to establish the joint variation of two or more variables for determining the amount of correlation between and/ or among variables. Correlation coefficient and the coefficient of determination helped assess the strength of relationship between dependent and one or more independent variables. Inferential techniques were useful for testing hypotheses to determine with what validity data can be said to indicate the conclusions (Kothari, 2004 130). In scientific researches, it is mainly on the basis of inferential analysis that the task of interpretation is performed.

SPSS software was useful for analyzing large data (Dzis, 2008 39) in this study. It was used to reduce the data into manageable size through factor analysis to identify the structure underlying them. Reliability testing was conducted for each factor to ascertain the degree to which the items making up the scale agreed, thus find out whether all the variables collated on one factor have internal consistency and measure the same underlying constructs (Brace et al,. 2003; Bryman \& Cramer, 2004; Hair et al., 2006; Pallant, 2005 in Dzis, 2008 46).

\section{Results}

- $\mathrm{H}_{1}$.There is a significant relationship between entrepreneurs' motives and their ventures' growth. Scales for motives and venture growth were regressed to determine how well entrepreneurs' motives influenced venture growth. The results showed a significant influence of entrepreneur's motives on growth, in that $b=.6239, t=$ 
13.3237 and $p=<001$. The $R$-squared value $\left(R^{2}=3225\right)$ means that the regression model explained $32 \%$ of the relationship.

- $\mathrm{H}_{2}$. There is a significant relationship between entrepreneurs' motives and resource support. The outcome showed how much of the influence variance the independent variables (motives) explained in the dependent variable (resource support). The results showed a significant influence of entrepreneur's motives on resource support, in that $b=-.3580, t=-7.3973$ and $p=<001$. The $R$-squared value $\left(R^{2}=.1279\right)$ means the regression model explained $13 \%$ of the relationship. It is important to note that negative $b$ value $(b=-.358)$ means women entrepreneurs' motives relate negatively to resource support programs (negative slope of the curve).

- $\mathrm{H}_{3}$. There is a significant relationship between resource support and venture growth. Simple regressions allowed the study to determine how well this independent variable - resource support programs by the Kenyan government were able to influence the dependent variable - women-owned MSE growth. The regression results showed a significant influence of entrepreneur's traits on growth, in that $b=.5455, t=11.1533$ and $p=<.001$. The Rsquared value $\left(\mathrm{R}^{2}=3572\right)$ means that the regression model explained $36 \%$ of the relationship. Research has proved the importance financial capital to the growth of entrepreneurial ventures. Human capital consisting of business skills and knowledge derived from education, previous work experiences, entrepreneurial mentorship and material/ tangible capital have been found to differentiate levels of entrepreneurial activity among female (Brush et al., 2006 228).

Literature shows that availability of human, material and networks is crucial at venture start-up, determining success and survival. This hypothesis assessed the influence of the government's resource support on women-owned MSE growth. Since the LLCI interval did not include $(.4493, .6416)$ zero, this study concluded that there is significant influence of resource support on women-owned MSEs' growth, and accepted the seventh alternative hypothesis.

- $\mathrm{H}_{4}$. There is a significant mediating influence of resource support in the relationship between entrepreneurs' motives and venture growth. The use of a series of regressions allowed the study to determine how well effect of independent variable - entrepreneur's motives traits enhanced by the mediator - resource support influenced the dependent variable - growth of female-owned ventures. The first step results showed significant mediating influence of resource support in the relationship between entrepreneurs' motives and venture growth; $b=.0784$, BCa CI $(.0443, .1207)$. Also, the R-squared (R-sq med=1075) means the model explained $11 \%$ of the mediation relationship. The Preacher and Kelley Kappa-squared, $\mathrm{k}^{2}=.0829,95 \%$ BCa CI $(.0493, .1227)$, further shows that there is a small but significant indirect relationship between entrepreneur's traits and growth through resource support, meaning that there are other mediators other than entrepreneurs' profile. This is further supported by the normal theory tests for indirect effect where $b=.0784, \mathrm{z}=3.8087$ and $\mathrm{p}=<001$.

Basing on the resource-based theory therefore, statistical modelled below was derived.

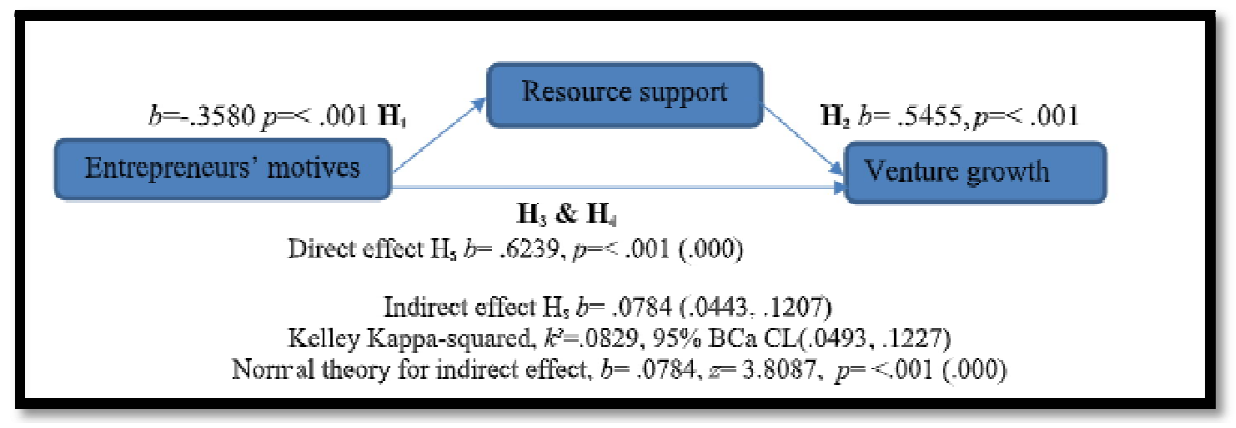

Figure1: Statistical Models for Hypotheses $\mathrm{H}_{1}-\mathrm{H}_{4}$, Anchored on the Resource-Based Theory

\section{References}

i. Bryman, A. (2006). Integrating quantitative and qualitative research: how is it done? Qualitative Research, Vol. 6, pp. 97-113.

ii. Bwisa H. M. \& Ongachi R. N. (2013). Factors Influencing Growth of Women Enterprises; A Survey of Kitale Municipality. International Journal of Academic Research in Business and Social Sciences, October 2013, Vol. 3, No. 10 ISSN: 2222-6990

iii. Cochran, W. G. (1963). Sampling Techniques, (2nd Ed). John Wiley and Sons, Inc.: New York.

iv. Dzisi S. (2008). Women entrepreneurs in small and medium enterprises (SMEs) in Ghana. Unpublished PhD thesis submitted to the Australian Graduate School of Entrepreneurship, Faculty of Business and Enterprise. Swinburne University of Technology: Victoria, Australia

v. ESCAP (July 2015). Unlocking the potential of women's entrepreneurship in South Asia.

vi. Field A. (2013). Discovering Statistics Using IBM SPSS Statistics. Sage International Ltd.

vii. Hair, J.F., Black, B., Babin, B., Anderson, R.E. \& Tatham, R.L. (2006). MultivariateData Analysis (6th edn). Pearson Education: Harlow.

viii. Ingrid Verheul (2005). Is there a (fe)male approach? Understanding gender differencesin entrepreneurship. Unpublished PhD thesis submitted to Erusmus Research Institute of Managemnt: Rotterdam.

ix. Kothari, C.R. (2004). Research Methodology; Methods and Techniques (2nd Ed.).New AgeInternational (P) Ltd: New Delhi. 
x. KAM (2018): Manufacturing Priority Agenda; Sparking Kenya's Industrial Transformation for

Job Creation. Nairobi, Kenya.

xi. Leedy, P.D. \& Ormrod, J.E. (2005). Practical research: Planning and design (8th ed). Pearson Education Inc: New Jersey.

xii. Marlow, S., Shaw, E. \& Carter, S. (2008). 'Constructing Female Entrepreneurship Policy in the UK: Is the USA a Relevant Role Model?', Environmental Planning.

xiii. Neuman, L (2006). Social Research Methods: Qualitative and Quantitative Approaches (6th edn). Pearson: Boston.

xiv. Noguera M. (2012). Female entrepreneurship in Catalonia: An institutional approach. Unpublished PhD thesis presented to Universitat Autonome de Barclona.

xv. OECD (2017). Strengthening Women's Entrepreneurship in ASEAN; “Towards increasing women's participation in economic activity". The OECD ASEAN Report.

xvi. ROK (2012). Ministry of Gender, Children and Social Development, Women Enterprise Fund Status of Female Enterprise Fund. Government Printer: Nairobi.

xvii. ROK (2009). Ministry of Gender, Children and Social Development, Women Enterprise Fund Strategic Plan 2009 2012. Government Printer: Nairobi.

xviii. Sangurah R. M. Robbert (2018). Influence of Niche Policy on Women Entrepreneurial Activity in Western Kenya Counties. Unpublished PhD thesis submitted to the School of Business and Economics. Moi University

xix. Saunders, M. Lewis P. \& Thormill, A. (2009). Research Methods for Business Students (3rd ed).Prentice Hall: England.

xx. Schwartz E. B. (1976). Enrepreneurship; a new female frontier. Journal of Contemporary Business. 5, 47-76.

xxi. United Nations (2016): The Sustainable Development Goals Report. UN: New York\& Geneva

xxii. UNDP (2013). Kenya's Youth Employment Challenge. Discussion Paper, January 2013

xxiii. UNIDO (2003). A path out of poverty; Developing rural and women Entrepreneurship. Vienna 